\title{
Mariusz Książek \\ The research on thermoplastic properties cement composites impregnated with the waste of sulfur
}

Received: 28 April 2016 / Revised: 8 June 2016 / Published online: 29 July 2016

(C) The Author(s) 2016. This article is published with open access at Springerlink.com

\begin{abstract}
The process of creating special polymerized sulfur composites through application of industrial waste material is a thermal treatment process in the temperature of about $150-155^{\circ} \mathrm{C}$. The result of such treatment is a special polymerized sulfur composite in a liquid state. This paper presents the effective plastic constants and coefficients of thermal expansion of stochastic special polymer sulfur composites, with isotropic porous matrix, reinforced by disoriented ellipsoidal inclusions with orthotropic symmetry of the thermoplastic properties. The investigations are based on the stochastic differential equations of solid mechanics. A model and algorithm for calculating the effective characteristics of special polymer sulfur composites are suggested. The effective thermoplastic characteristics of special polymer sulfur composites, with disoriented ellipsoidal inclusions, are calculated in two stages: First, the properties of materials with oriented inclusions are determined, and then, effective constants of a composite with disoriented inclusions are determined on the basis of the Voigt or Rice scheme. In this paper, the review of the literature has been done, among other things, about selecting and using special polymerized sulfur coating in buildings, about the methods of surface protection against corrosion of concretes, and about the methods of the evaluation of the protection layer on these materials. Special polymerized sulfur as polymer coating impregnation, which has received little attention in recent years, currently has some very interesting applications. An innovative overlay for use in areas where freezing and thawing are prevalent has been developed.
\end{abstract}

\section{Introduction}

Czarnecki et al. [1] and Hoła et al. [2] found that at ambient temperature, special sulfur coating created from industrial waste material crystallizes in the rhombic system $\left(\alpha\right.$-S). It melts at the temperature $105-110^{\circ} \mathrm{C}$ and crystallizes from this melt to the form of $\beta-\mathrm{S}$ (monocyclic) which changes again to the $\alpha-\mathrm{S}$ at $95-96^{\circ} \mathrm{C}$ (thermoplastic properties) [1-3].

Melted sulfur polymerizes as discussed and published elsewhere [3-8]:

- at $160^{\circ} \mathrm{C}$, it is brown and indicates increased viscosity,

- between 200 and $250^{\circ} \mathrm{C}$ it is dark brown with high viscosity value,

- at $250^{\circ} \mathrm{C}$, depolymerization and diminishing of viscosity begins; at $400^{\circ} \mathrm{C}$, sulfur is very fluid,

- $444.6^{\circ} \mathrm{C}$ is the temperature of its boiling. The rapid process of cooling sulfur in water changes it from the fluid state to an elastic-plastic body, brown-yellow colored. In this state, sulfur is composed of two different polymerized forms: $\mathrm{S}_{\lambda}$ (yellow) and $\mathrm{S}_{\mu}$ (dark red-brown). $\mathrm{S}_{\mu}$ has a higher molecular mass.

M. Książek (凶)

Division of Building Materials, Timber and Monumental Heritage Structures, Faculty of Civil Engineering,

Wrocław University of Technology, pl. Grunwaldzki 11, 50-377 Wrocław, Poland

E-mail: ksiazekmariusz@wp.pl 
Sulfur may be obtained in the colloidal state as discussed, e.g., in [21-24]:

- after boiling with water and $\mathrm{Ca}(\mathrm{OH})_{2}$, and precipitation with $\mathrm{HCl}-\mathrm{S}_{\mu}$

- after hydrolysis of alcohol solution- $\mathrm{S}_{\lambda}$.

Ramli et al. [23] found that from the chemical reactivity point of view, sulfur may be oxidized and as well easily reduced (it forms many sulfides and organo-sulfur compounds). Elementary sulfur rarely finds applications. It is used in the production of some kinds of cement for special purposes, e.g., to join ceramics and metallic parts of electric insulators and in the industrial objects. The mechanical properties of this cement are good (strength about 50-60 MPa by compression), and its chemical inertness is appreciated (in comparison with Portland cement-containing concretes). Sulfur is also used in dermatology [6-10].

Milica et al. [24] and Książek [9-14] found the functional properties of the special polymerized sulfur coating and sulfur polymer-based products. Orthorhombic special polymerized sulfur is also subject to deterioration by bacteria, sunlight, very strong alkalies, and thermal fluctuations.

Czarnecki et al. [1] and Hoła et al. [2,3] found that the polymer-cement concretes (PCC), obtained by adding special polymerized sulfur coating to the concrete mix, are a diverse set of composites, usually with better consistency of the concrete mix and increased - as compared to the ordinary concrete- tensile strength, as well as many other modified thermoplastic properties.

Czarnecki et al. [1] and Książek [12-16] found that the special polymerized sulfur coating-impregnated concretes (PIC) are basically different from all other types of polymer concretes. In this case, the special sulfur polymer is introduced into the hardened cement concrete. The result is an extraordinary increase in the tightness, manifesting itself by tenfold or even 20 -fold downfall of the absorbability, from $4 \%$ for unmodified concrete to $0.30-0.16 \%$ for impregnated concrete. The consequence of filling of the pores with special sulfur polymer is also a twofold to fourfold increase in compressive strength, twofold to threefold increase in tensile strength, and fourfold decrease in the diffusion coefficient. PIC show more than three times lower creep. PIC (concretes impregnated with special polymerized sulfur composite) have very high chemical resistance, significantly decreased penetration of chloride ions, and improved frost resistance. Practically, the only disadvantage of PIC is the sudden mode of failure; the modulus of elasticity can reach $45 \mathrm{GPa}(45,000 \mathrm{MPa})$. This inconvenience can be eased, to some extent, by introduction of suitable impregnating copolymers. We can assume, therefore, that we have on disposal the perfect concrete, durable and with excellent technical features. The special sulfur polymer-impregnated concretes (PIC) are not widely implemented. There is a factory producing precast elements of PIC in Japan, manufacturing pipes and other elements of the underground infrastructure. There is also a company offering the impregnation services in Germany, aimed at the conservation of stone objects. Repairs of the bridge pavements and surfaces of the water dams have been performed in the USA in the seventies (Dvorshak Dam in Idaho). The repairs consisted in the superficial impregnation of the previously dried concrete to the depth of several cms. The concrete was periodically heavily sprinkled with the special polymerized sulfur composite and spilled with fine-grained sand for limiting the special polymerized sulfur composite evaporation. A prototype machine with suckers was employed on the bridges; the machine sucked out the air from the dried concrete and then forced the special polymerized sulfur composite into the concrete under pressure [1].

Czarnecki et al. [1] and Kamiński et al. [4] found that the external surfaces of the concrete are protected with the plastic sheet to avoid the polymer evaporation. The impregnation is initiated thermally, by steam or immersion in hot special polymerized sulfur composite at a temperature above $80^{\circ} \mathrm{C}$ for several hours. The research works (not numerous presently) are involved in simplification of the technological process. They are aimed at elimination of air-sucking, with only necessary preparation by concrete drying and with replacement of the pressure impregnation by a gravitational one. The thorough impregnation of elements of a thickness up to $10 \mathrm{~cm}$ is possible this way. The process can be intensified to $30 \mathrm{~cm}$ and perhaps even $50 \mathrm{~cm}$ by introducing suitably distributed venting ducts into the impregnated element. There is also the concept of forming the concrete microstructure during prefabrication, increasing the impregnation susceptibility. The above considerations show that the concept of PIC is very attractive regarding the technical properties of the product. The barrier is a complicated technological process, almost impossible to perform on existing objects. The impregnation of precast concrete pipes seems to be the most promising and purposeful application [14].

Czarnecki et al. [1] and Książek [14-18] found that the tremendous increase in properties was offset by the complexities of the impregnation process: drying to remove all of the moisture, evacuating the air, applying the special polymerized sulfur under pressure to fully impregnate the concrete, and the application of heat or irradiation to fully polymerize the monomer. To fully impregnate large precast components such as several city collectors, bridge girders, bridge deck slabs, piling, and wall panels would require a large, efficient 
facility that would be difficult to justify unless it could be shown that a market for a large volume of PIC products would be forthcoming. No such facility has ever been developed in Poland. Until some breakthroughs in process technology are realized, there is little likelihood that fully impregnated PIC members will ever become economically feasible. This is unfortunate since PIC has such exceptional strength and durability properties [1,14-18].

Let us examine a representative volume $V$ of the thermoelastic special polymer sulfur composite as randomly inhomogeneous medium, at each point $x^{(1)}$ for which the Duhamel-Neimann law [25-27] is given by:

$$
\begin{aligned}
\sigma_{i j}^{(1)} & =\lambda_{i j \alpha \beta}^{(1)} \varepsilon_{\alpha \beta}^{(1)}-\beta_{\mathrm{ij}}^{(1)} \theta ; \\
\beta_{i j}^{(1)} & =\lambda_{i j m n}^{(1)} \alpha_{m n}^{(1)},
\end{aligned}
$$

the equilibrium equations [25-27]:

$$
\sigma_{i j, j}=o
$$

and the Cauchy relationship [25-27]:

$$
\varepsilon_{i j}^{(1)}=1 / 2\left(u_{i, j}^{(1)}+u_{i, j}^{(1)}\right)
$$

are valid, where $\sigma_{i j}$ and $\varepsilon_{i j}$ are the stress and strain tensors, $\lambda_{i j \alpha \beta}$ is the tensor of elastic constants, $\beta_{i j}$ and $\alpha_{m n}$ are the tensors of the coefficients of temperature stresses and the coefficients of linear thermal expansions, respectively, $\theta$ is the temperature increase, and $u_{i}$ are the displacements [25-27].

When the representative volume is acted upon by a uniform load and heating, the stresses and strains that develop within this body form statistically homogeneous random fields satisfying the property of ergodicity. This makes it possible to replace the operation of averaging over an ensemble of realizations. For macroscopic fields, we can write [25-27]:

$$
\left\langle\sigma_{i j}\right\rangle=\lambda_{i j \alpha \beta}^{*}\left\langle\varepsilon_{\alpha \beta}\right\rangle-\beta_{\mathrm{ij}}^{*} \theta ; \quad \beta_{i j}^{*}=\lambda_{i j m n}^{*} \alpha_{m n}^{*},
$$

where $\lambda_{i j m n}^{*}$ and $\alpha_{m n}^{*}$ are tensors of the effective elastic constants and the temperature expansion coefficients [25-27].

Consider a special polymer sulfur composite reinforced by randomly distributed and randomly directed ellipsoidal inclusions. This composite may be regarded as a set of subsystems; each subsystem consists of a composite with oriented inclusions, the symmetry axes of which are directed in a certain manner relative to the initial coordinate system of the composite as a whole. Consider such a subsystem and suppose that the inclusions are orthotropic, oriented ellipsoids and the geometric axes of the ellipsoids coincide with the orthotropy axes of the thermoelastic modulus tensor. The orientation of the coordinate axes of the subsystem $x_{1}, x_{2}, x_{3}$ relative to the basic coordinate system of the material $x_{1}^{\prime}, x_{2}^{\prime}, x_{3}^{\prime}$ will be described by directional cosines as follows [25-27]:

$$
x_{i}^{\prime}=a_{i k} x_{k}
$$

The directional cosines may be expressed in terms of Euler angles as follows [25-27]:

$$
\begin{aligned}
& a_{11}=\cos \psi \cos \varphi-\cos \theta \sin \psi \sin \varphi ; \quad a_{21}=-\cos \psi \sin \varphi-\cos \theta \sin \psi \cos \varphi \\
& a_{31}=\sin \theta \sin \psi ; \quad a_{12}=\sin \psi \cos \varphi+\cos \theta \cos \psi \sin \varphi ; \quad a_{13}=\sin \theta \sin \varphi ; \\
& a_{22}=-\sin \psi \sin \varphi+\cos \theta \cos \psi \cos \varphi ; \quad a_{32}=-\sin \theta \cos \psi ; \\
& a_{23}=\sin \theta \cos \varphi ; \quad a_{33}=\cos \theta ; \quad(0 \leq \theta<\pi ; 0 \leq \varphi<2 \pi ; 0 \leq \psi<2 \pi)
\end{aligned}
$$

Then, it follows from the conversion formulas for the components of tensors of fourth and second ranks on transition from the coordinate system $x_{i}$ to $x_{i}^{\prime}$ that [25-27]:

$$
\lambda_{i j \alpha \beta}^{* \prime}=a_{i m} a_{j n} a_{\alpha k} a_{\beta l} \lambda_{m n k l}^{*} ; \quad \beta_{\mathrm{ij}}^{* \prime}=a_{i m} a_{j n} \beta_{m n}^{*} .
$$

Then, introducing the distribution function that describes the spread of the coordinate axes of the subsystems relative to the Euler angles $f(\theta, \varphi, \psi)$, the mean value of the thermoplasticity coefficients may be written 
in the form of an integral with respect to all three angles [25-27]:

$$
\begin{aligned}
\left\langle\lambda_{i j k l}^{*}\right\rangle & =\frac{1}{8 \pi^{2}} \int_{0}^{\pi} \int_{0}^{2 \pi} \int_{0}^{2 \pi} f(\theta, \varphi, \psi) \lambda_{i j k l}^{* \prime}(\theta, \varphi, \psi) \sin \theta \mathrm{d} \theta \mathrm{d} \varphi \mathrm{d} \psi ; \\
\left\langle\beta_{i j}^{*}\right\rangle & =\frac{1}{8 \pi^{2}} \int_{0}^{\pi} \int_{0}^{2 \pi} \int_{0}^{2 \pi} f(\theta, \varphi, \psi) \beta_{i j}^{* \prime}(\theta, \varphi, \psi) \sin \theta \mathrm{d} \theta \mathrm{d} \varphi \mathrm{d} \psi .
\end{aligned}
$$

Thus, the approximate determination of the thermoplastic constants of the special polymer sulfur composites may be divided in two stages: First, the properties of the special polymer sulfur composites with oriented and randomly distributed inclusions are determined; then, the properties of the subsystems oriented in a certain manner, relative to the axes of the basic coordinate system, are calculated, and the effective properties of the whole system are determined by using the specified distribution function. The first stage is based on a model of the special polymer sulfur composites of stochastic structure reinforced by oriented ellipsoids. The effective properties of these special polymer sulfur composites, with orthotropic components, may be determined by using the method of conditional moment functions, and the second stage is based on the Voigt scheme, as outlined above, or on the Rice scheme (the elastic-pliability and the coefficients of linear thermal expansions tensors are averaged) [25-27].

In this case, Eq. (9) takes the form [25-27]

$$
\begin{aligned}
\left\langle S_{i j k l}^{*}\right\rangle & =\frac{1}{8 \pi^{2}} \int_{0}^{\pi} \int_{0}^{2 \pi} \int_{0}^{2 \pi} f(\theta, \varphi, \psi) S_{i j k l}^{* \prime}(\theta, \varphi, \psi) \sin \theta \mathrm{d} \theta \mathrm{d} \varphi \mathrm{d} \psi ; \\
\left\langle\alpha_{i j}^{*}\right\rangle & =\frac{1}{8 \pi^{2}} \int_{0}^{\pi} \int_{0}^{2 \pi} \int_{0}^{2 \pi} f(\theta, \varphi, \psi) \alpha_{i j}^{* \prime}(\theta, \varphi, \psi) \sin \theta \mathrm{d} \theta \mathrm{d} \varphi \mathrm{d} \psi
\end{aligned}
$$

where $S_{i j k l}^{*}=\lambda_{i j k l}^{*-1}$ and $S_{i j k l}^{* \prime}$ is determined by analogy with Eq. (8) [25-27].

The special coating with sulfur polymer composites from industrial waste, sets new standards and allows you to use sulfur concrete extensively in the road construction industry. Considerable savings owing to longer life and resistance to corrosion plus the thickness of the road base layer are self-evident, especially in regions with harsh climate, such as Siberia, the Far East, and the north of Russia and Canada, as discussed elsewhere [2,5-10].

The special coating with sulfur polymer composites applied as industrial waste material means not only advantages for the user, but also benefits for the environment, including low $\mathrm{CO}_{2}$ emission and low energy input for the process of waste stabilization and product prefabrication. Virtually waste-free, this technology does not require using water, and every product is $100 \%$ recyclable without any loss or waste as discussed and published elsewhere [2-4,8-14].

Benefits of the sulfur polymer composites are discussed, e.g., in [3-5,12-16].

Functional properties of the sulfur polymer composites are discussed, e.g., in [2-7].

\section{Materials and methods}

Special polymerized sulfur (polymer coating) applied from industrial waste material was investigated in two stages. In the first stage, compositions were fixed and thirty test specimens were prepared and pretested. The pretesting included preparing special polymerized sulfur and determining their basic physical, chemical, and mechanical properties, such as thermoplastic properties, bulk density, absorbability by weight, bending strength, and splitting tensile strength. The experimental details and results are reported in Książek [5-22].

Sulfuric binder applied in industrial waste is shown in Fig. 1.

The composition of the sulfur binder for industrial waste is $97.86 \% \mathrm{~S}_{8}$, fine sulfur, oil: $2.13 \%$, ash: $0.01 \%$, the producer is "Siarkopol" Tarnobrzeg. The composition of the sulfuric binder is shown in Table 1. 


\section{Impregnation technique}

Preparations consisted of melting special polymerized sulfur (polymer coating) at the temperature $150-155^{\circ} \mathrm{C}$ and then cooling to the ambient temperature. The samples and elements were immersed for 5-10 min and the remaining specimens for $0.5 \mathrm{~h}$ in molten special polymer sulfur coating. The specimens were then removed from the steel vessel, and excess liquid sulfur on the surface was wiped off. The samples and elements were cooled in water for $20 \mathrm{~min}$, in order to crystallize the sulfur in the surface pores and prevent loss of sulfur by evaporation, and were then left at room temperature to cool in the air. The specimens were weighed before and after impregnation, and sulfur loading was calculated. The impregnated specimens looked shiny greenish to dark gray depending upon the original color of the specimens (Fig. 2). However, the rough texture was not affected very much. The total process time is $0.20-0.30 \mathrm{~h}(20-30 \mathrm{~min})$ for samples and elements. Details were published in [5-10].

The samples of concrete and cement mortar impregnated with special polymerized sulfur (polymer coating) applied are shown in Fig. 2.

The impregnation caused saturation of the pores of the cement composites and strain hardening of the surface. The scheme of impregnation and repair of the cement composite surface is shown in Figs. 3 and 4, as discussed in Czarnecki and Emmons [1,5-9].

\section{(a)}
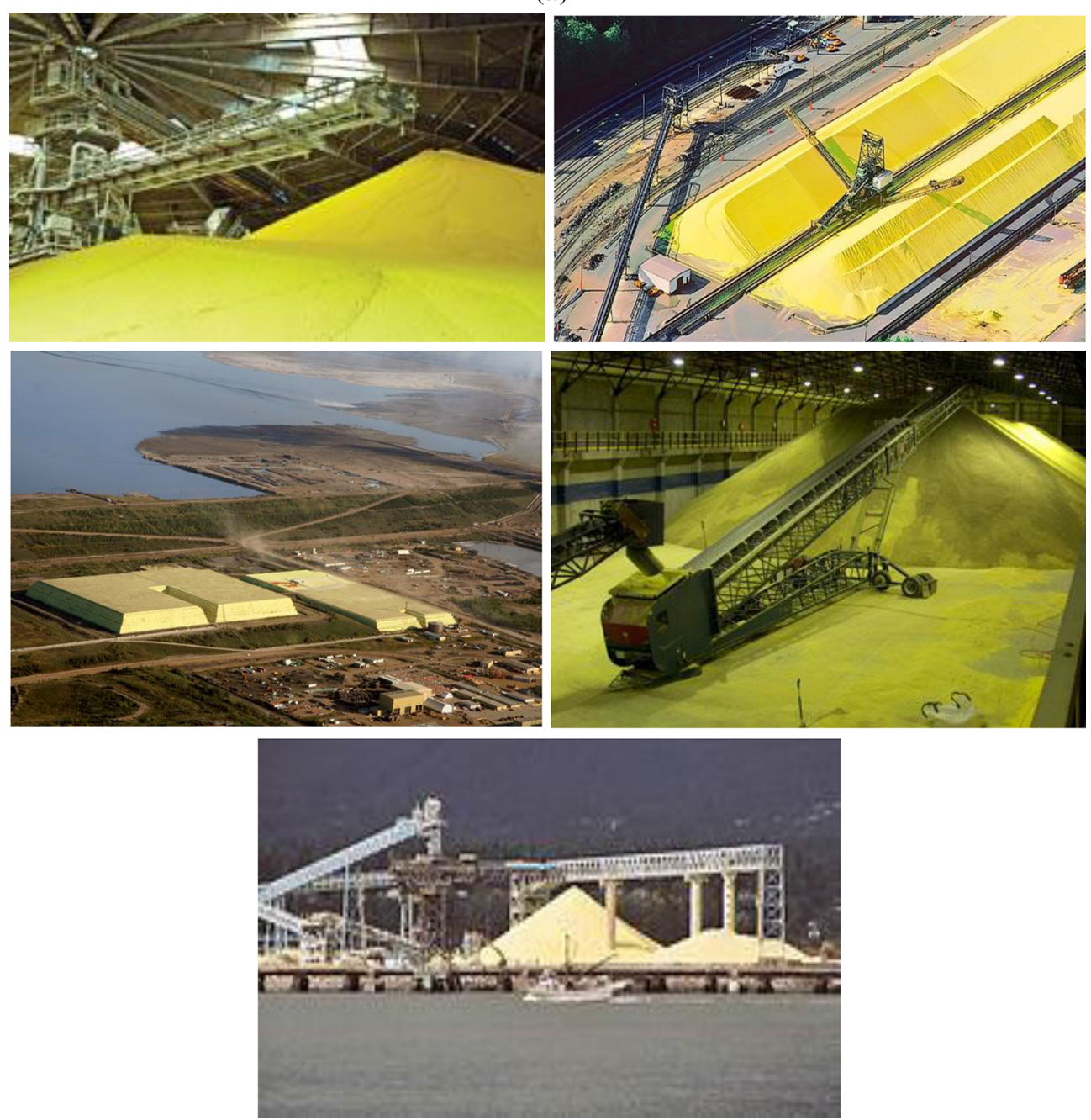

Fig. 1 View of the sulfuric binder applied as the industrial waste, $\mathbf{a}$ in Europe, $\mathbf{b}$ in Poland 
(b)
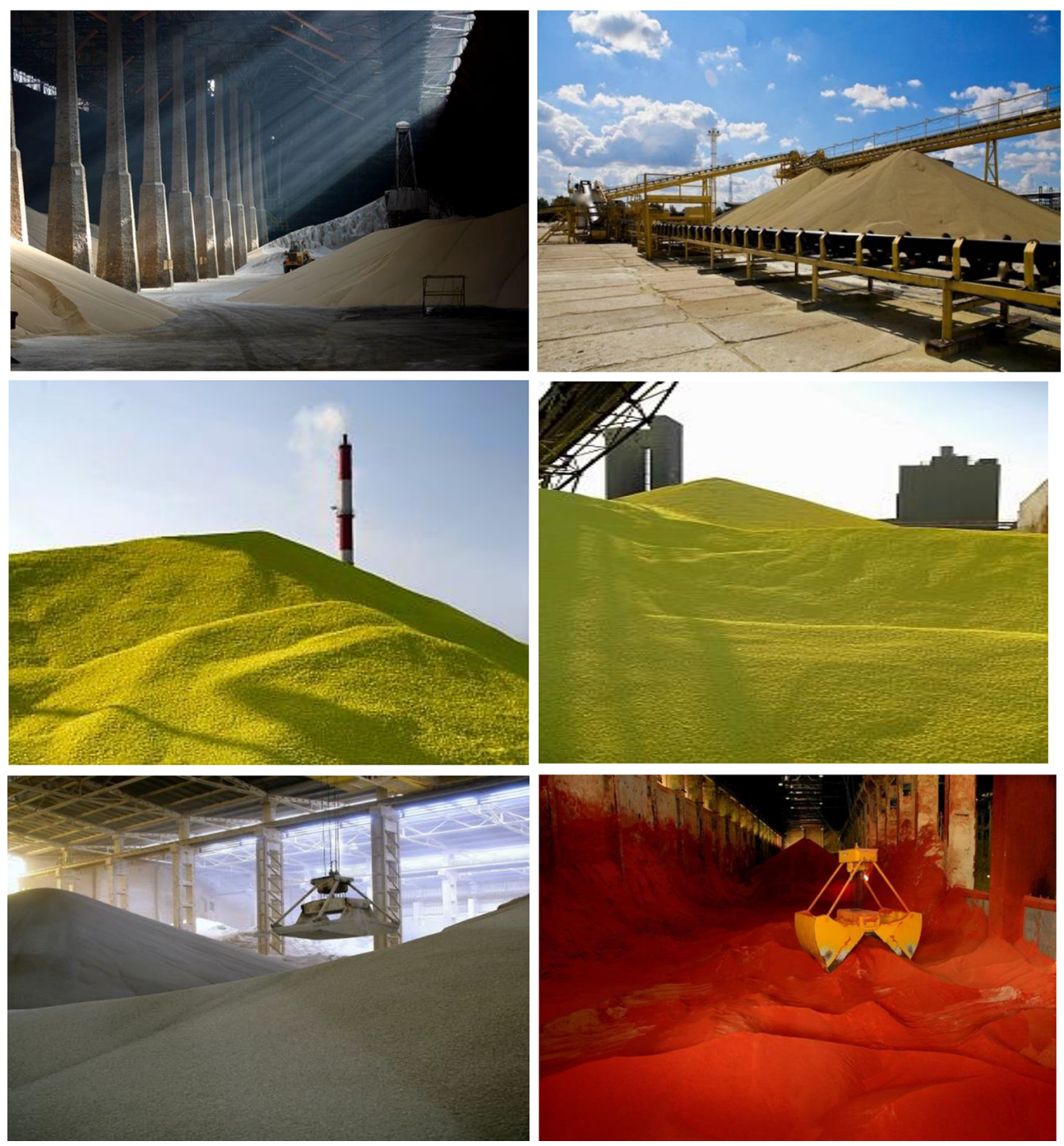

Fig. 1 Continued

Table 1 Compositions of the sulfuric binder applied as the industrial waste

\begin{tabular}{llc}
\hline & Component & Content (\%) \\
\hline 1 & Sulfur, $\mathrm{S}_{8}$ & 97.86 \\
2 & Oil & 2.13 \\
3 & Ash & 0.01 \\
4 & Leaven as $\mathrm{H}_{2} \mathrm{SO}_{4}$ & 0.001 \\
5 & Piece volatile & 0.02 \\
6 & Remainder on the sieve $0.063 \mathrm{~mm}$ & 0.01 \\
\hline
\end{tabular}

\section{Investigation results and comments}

\subsection{Thermoplastic properties}

The thermoplastic properties of special polymerized sulfur were examined. The sulfuric binder used in the investigations as the industrial waste is shown in Fig. 5. The thermoplastic properties of special polymerized sulfur as a function of temperature are shown in Fig. 6 [20-24]. 

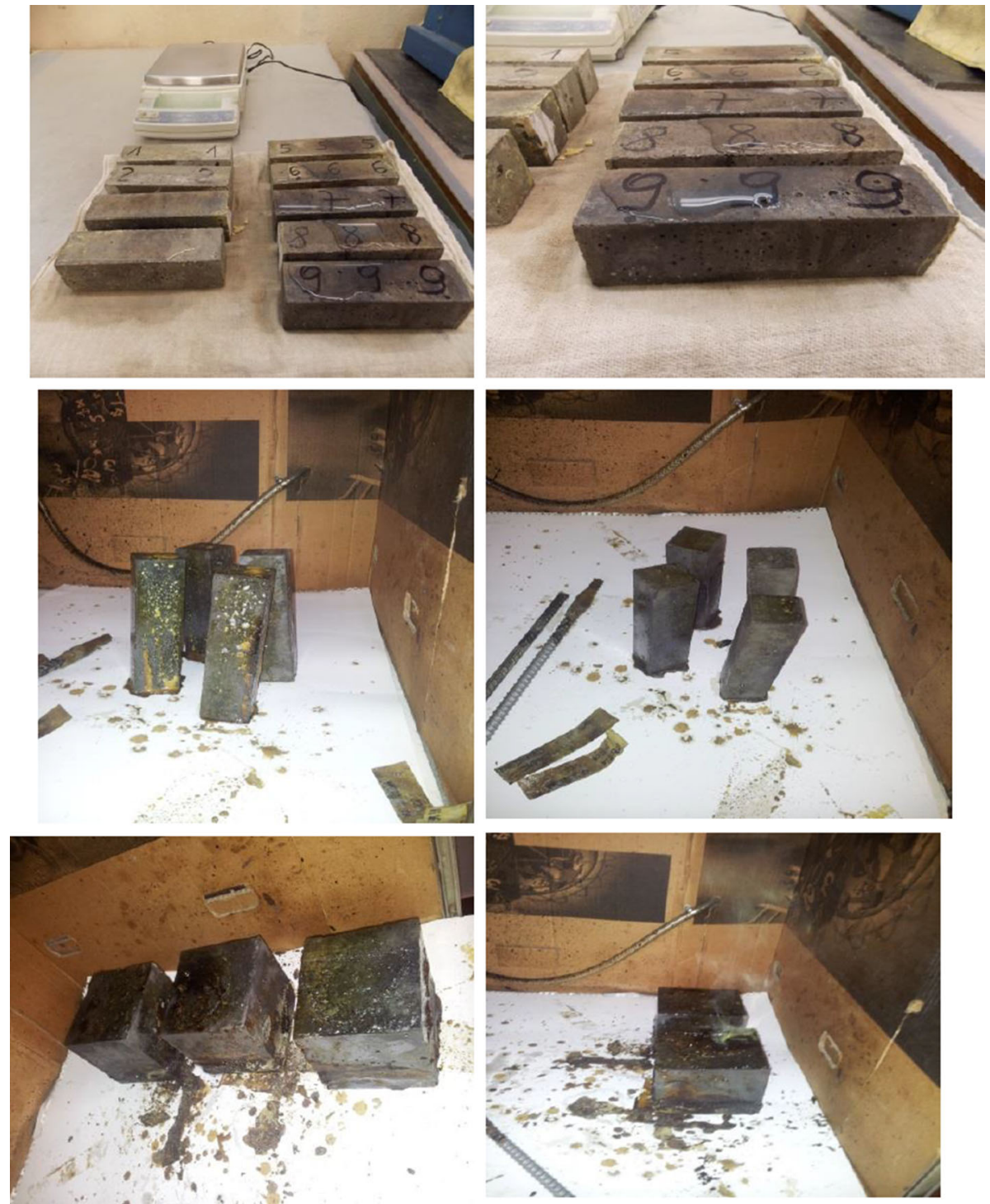

Fig. 2 View cement composites impregnated with the waste of sulfur
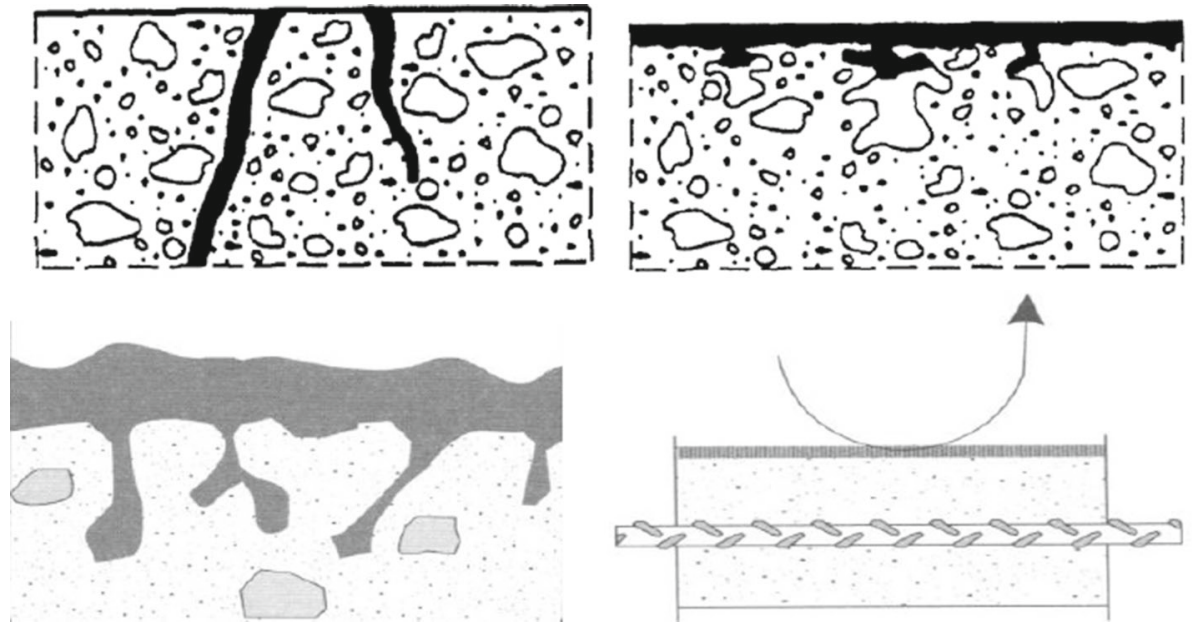

Fig. 3 Scheme of the impregnation and repair of the surface cement composites [1,5-9] 


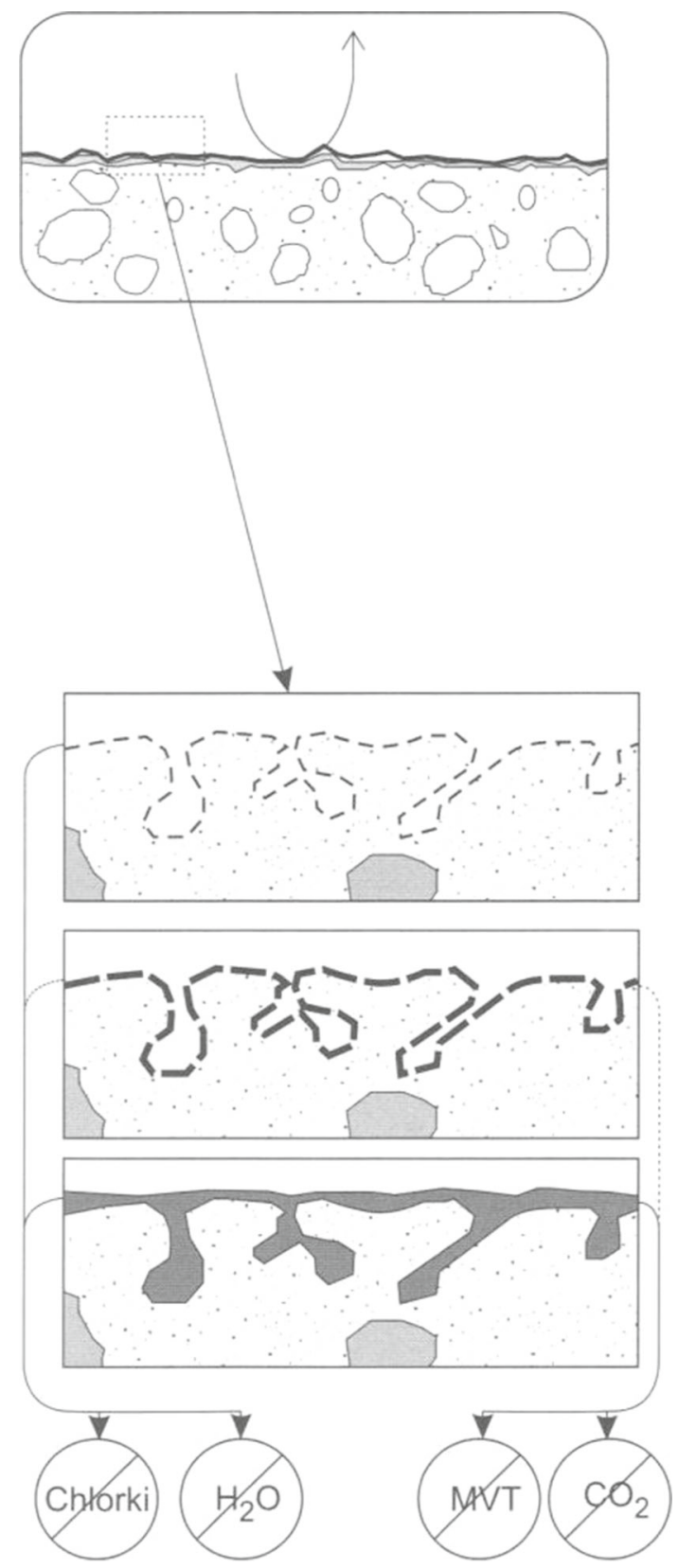

Fig. 4 View of the surface cement composites impregnated with the waste of sulfur [1,5-9]

Special polymerized sulfur possesses lemon yellow sintered microcrystals. The chemical element of the special polymerized sulfur and the spectral lines of special polymerized sulfur, applied as the industrial waste, are shown in Fig. 7 [18-24].

In 2008-2015, the author reported on research with special polymerized sulfur (polymer coating) infiltrated concrete and building mortar, and noted that waste sulfur has economical advantages over organic polymer. When the impregnation was vacuum assisted, an exceedingly strong and durable concrete and building mortar could be produced by precasting. The author did not recommend his particular formulation for cast-in-place use. In effect, the waste sulfur was used as a substitute for some of the Portland cement, because the concrete and building mortar, being infiltrated, had a water-to-cement $(\mathrm{w} / \mathrm{c})$ ratio of 0.70 , about $4.0 \mathrm{bag} / \mathrm{yd} \mathrm{d}^{3}$. In 2008-2015, it was concluded that at least in Poland, this infiltrated concrete and building mortar would probably be less costly than Portland cement concrete having a w/c of 0.40 . The sulfur-infiltrated concrete 
had a compressive strength of over $10.000 \mathrm{lb} . / \mathrm{in}^{2}\left(700 \mathrm{~kg} / \mathrm{cm}^{2}\right)$, withstood 200 cycles of freezing and thawing without damage, and was exceedingly resistant to chemical attack. Apparently, the special polymerized sulfur fills the capillaries and prevents absorption of water or chemicals, and this prevents the critical saturation that causes freeze-thaw distress. A personal communication from the author indicated that there had been no change in the properties of this laboratory concrete in 5 years [1-10].

Investigations were executed for a city collector. The city collector impregnated with special polymerized sulfur is shown in Fig. 8. The composition of concrete of the city collector is presented in Table 2. Details were given in [5-15].

The impregnation caused saturation of the pores of cement composites and strain hardening of the surface.

\subsection{Deduction of correlation for particular cases}

Several particular cases of a special polymer sulfur composites with disoriented inclusions are considered. Consider uniformly disoriented inclusions and the mean constants $\left\langle\lambda_{i j}^{*}\right\rangle$ and $\left\langle\beta_{i j}^{*}\right\rangle$ corresponding to Voigt averaging are calculated. Setting $f(\theta, \varphi, \psi)=1.0$ in Eq. (9), it is evident that the problem reduces to averaging the sum of the products of the directional cosines [2,25-27].

After substituting Eq. (8) into Eq. (9) and taking into account Eq. (7), the result obtained is [25-27]:

$$
\begin{aligned}
& \left\langle\lambda_{11}^{*}\right\rangle=\left\langle\lambda_{22}^{*}\right\rangle=\left\langle\lambda_{33}^{*}\right\rangle=1 / 5\left(\lambda_{11}^{*}+\lambda_{22}^{*}+\lambda_{33}^{*}\right)+2 / 5\left(\lambda_{12}^{*}+\lambda_{13}^{*}+\lambda_{23}^{*}+2 \lambda_{44}^{*}+2 \lambda_{55}^{*}+2 \lambda_{66}^{*}\right) ; \\
& \left\langle\lambda_{12}^{*}\right\rangle=\left\langle\lambda_{13}^{*}\right\rangle=\left\langle\lambda_{23}^{*}\right\rangle=1 / 15\left(\lambda_{11}^{*}+\lambda_{22}^{*}+\lambda_{33}^{*}\right)+4 / 15\left(\lambda_{12}^{*}+\lambda_{13}^{*}+\lambda_{23}^{*}\right)-2 / 15\left(\lambda_{44}^{*}+\lambda_{55}^{*}+\lambda_{66}^{*}\right) ; \\
& \left\langle\lambda_{44}^{*}\right\rangle=\left\langle\lambda_{55}^{*}\right\rangle=\left\langle\lambda_{55}^{*}\right\rangle=1 / 2\left(\left\langle\lambda_{11}^{*}\right\rangle-\left\langle\lambda_{22}^{*}\right\rangle\right) ; \quad\left\langle\beta_{11}^{*}\right\rangle=\left\langle\beta_{22}^{*}\right\rangle=\left\langle\beta_{33}^{*}\right\rangle=1 / 3\left(\beta_{11}^{*}+\beta_{22}^{*}+\beta_{33}^{*}\right) .
\end{aligned}
$$

Thus, it is evident that the special polymer sulfur composites consist of an isotropic medium in a macro-volume. The mean elastic-pliability matrix $\left\langle S_{i j}^{*}\right\rangle$ and the coefficients of linear thermal expansion $\left\langle\alpha_{m n}^{*}\right\rangle$,corresponding to Rice averaging, may be calculated analogously [25-27].

Consider the case in which the inclusions are uniformly and continuously distributed within the interval $0 \leq \theta<\theta^{*}, 0 \leq \varphi<2 \pi, 0 \leq \psi<2 \pi$, where $\theta^{*}$ is the maximum angle of fiber deviation from axes $x_{3}$. In this case, the distribution function $f(\theta, \varphi, \psi)$ will take the form [25-27]:

$$
f(\theta, \varphi, \psi)=a h_{\theta^{*}}(\theta)
$$

Here, $h_{\theta^{*}}(\theta)$ is the indicator function of the angle $\theta$ [25-27]:

$$
h_{\theta^{*}}(\theta)= \begin{cases}1 ; & \leq \theta \leq \theta^{*} \\ 0 ; & \theta^{*} \leq \theta \leq \pi\end{cases}
$$

and $a$ is found from the normalization condition [25-27]:

$$
\frac{1}{8 \pi^{2}} \int_{0}^{\pi} \int_{0}^{2 \pi} \int_{0}^{2 \pi} f(\theta, \varphi, \psi) \sin \theta \mathrm{d} \theta \mathrm{d} \varphi \mathrm{d} \psi=1
$$

Substitution of Eqs. (12), (13) into Eq. (14) gives [25-27]:

$$
a=\frac{2}{1-\cos \theta^{*}}
$$

and taking into account Eq. (12), it follows that [25-27]:

$$
f(\theta, \varphi, \psi)=\frac{2}{1-\cos \theta^{*}} h_{\theta^{*}}(\theta) .
$$



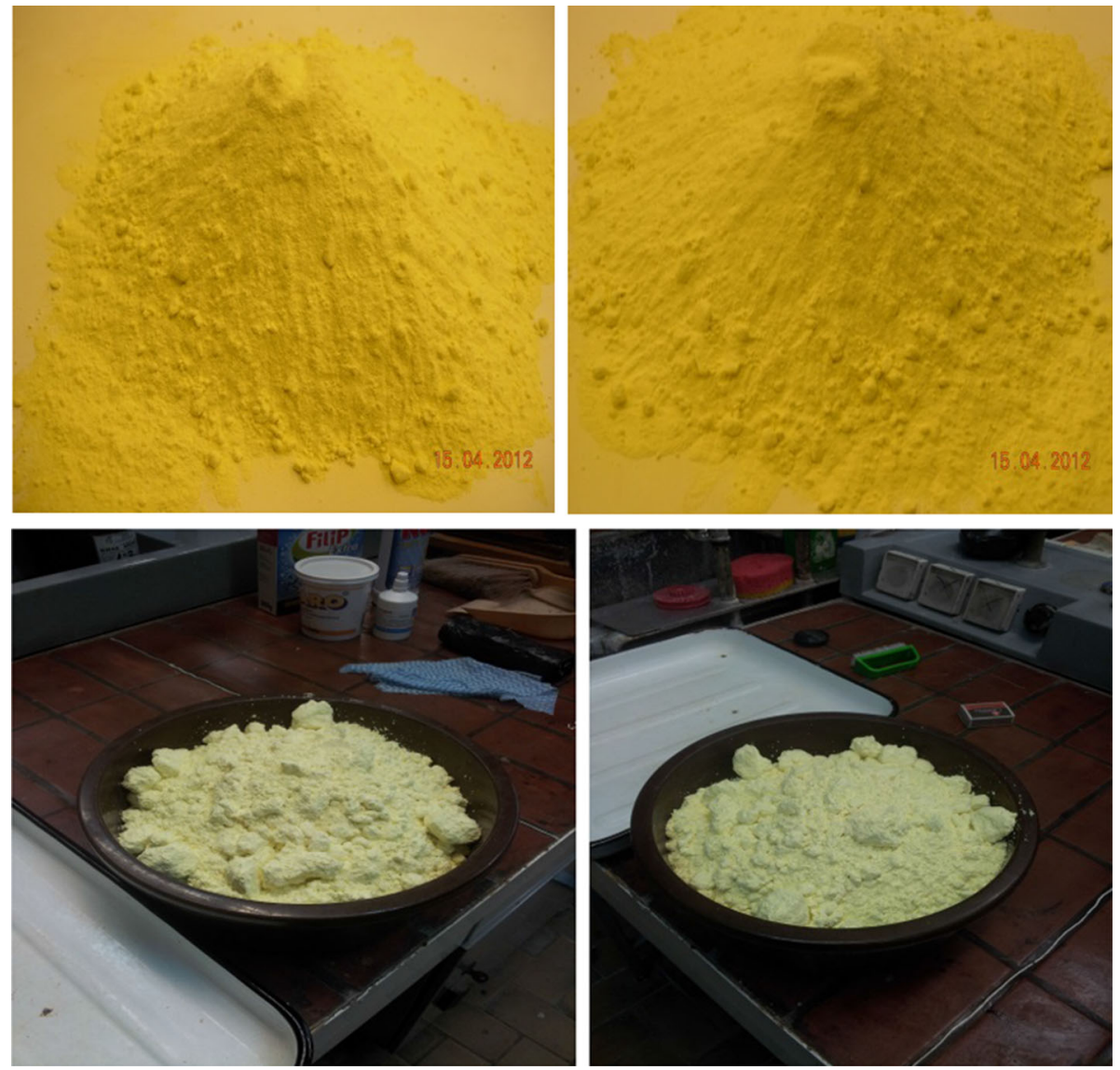

Fig. 5 View of the sulfuric binder used in the investigations
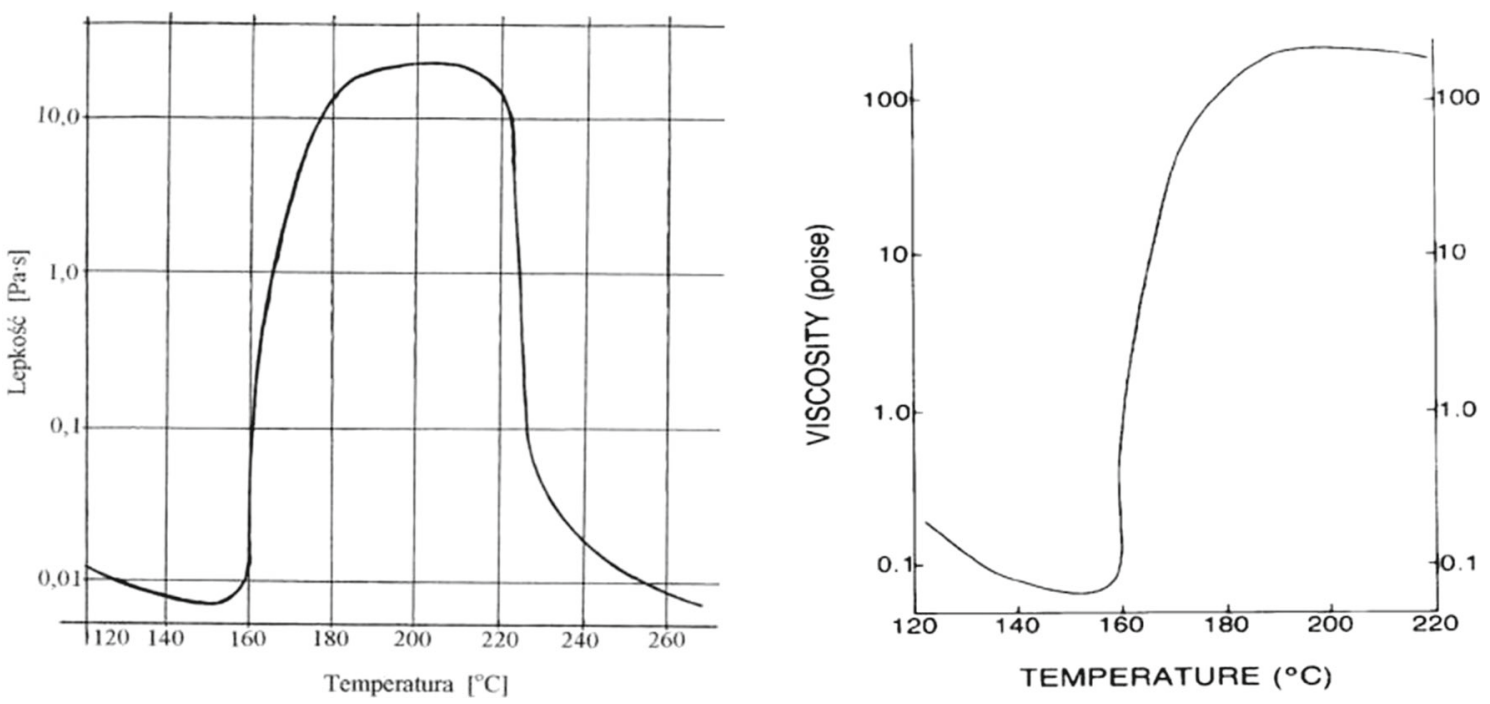

Fig. 6 View of the thermoplastic properties of special polymerized sulfur as a function of temperature [20-24] 


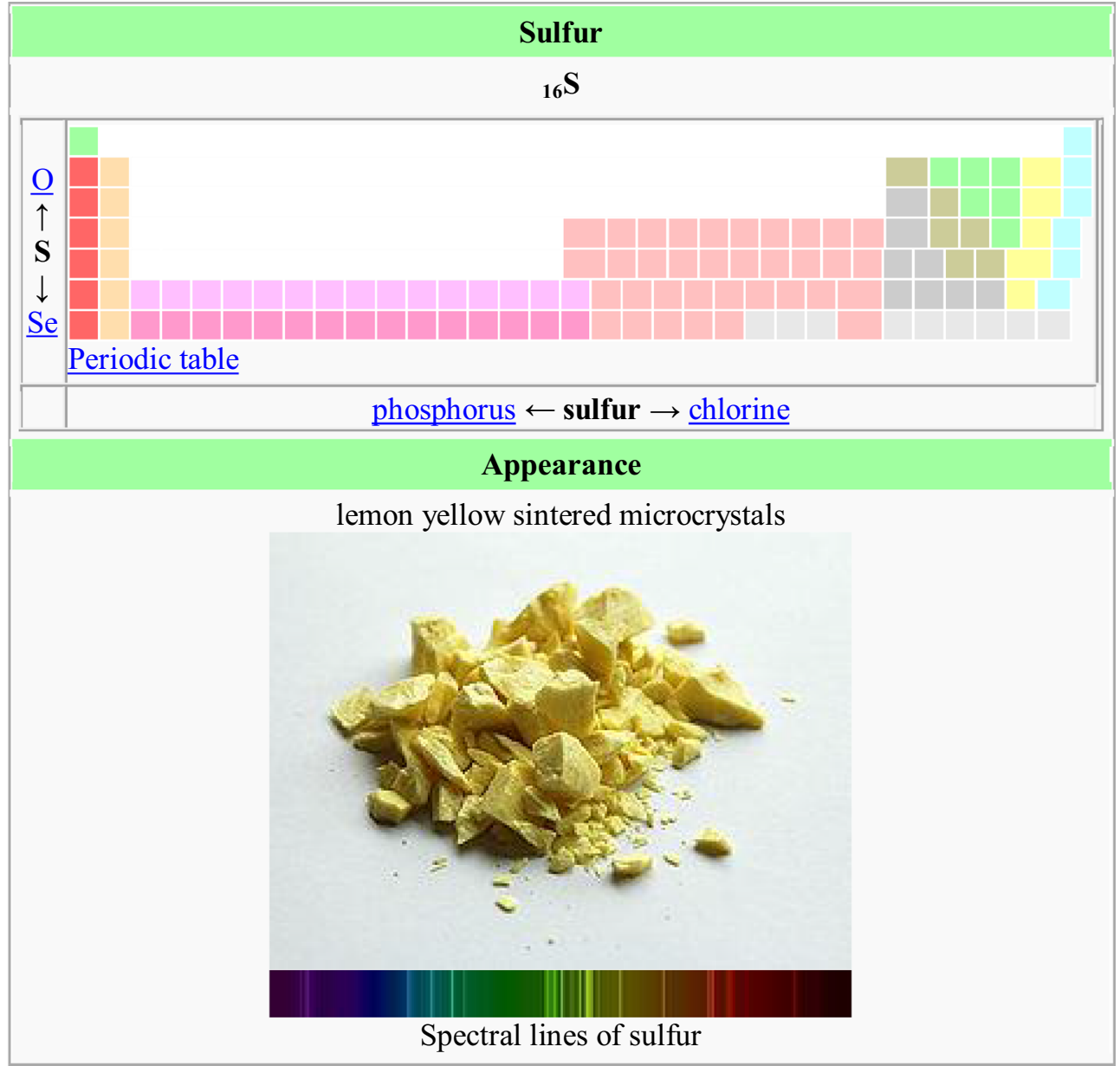

Fig. 7 View of the chemical element of special polymerized sulfur and the spectral lines of special polymerized sulfur [18-24]

Now, knowing $f(\theta, \varphi, \psi)$, the mean constants $\left\langle\lambda_{i j}^{*}\right\rangle$ and $\left\langle\beta_{i j}^{*}\right\rangle$ may be found from Eqs. (7) to (9). Omitting intermediate calculations, the mean thermoplastic moduli are as follows [25-27]:

$$
\begin{aligned}
& \left\langle\lambda_{11}^{*}\right\rangle=\left\langle\lambda_{22}^{*}\right\rangle=3 a_{1}\left(\lambda_{11}^{*}+\lambda_{22}^{*}\right)+3 a_{2} \lambda_{33}^{*}+2 a_{3}\left(\lambda_{23}^{*}+\lambda_{13}^{*}+2 \lambda_{44}^{*}+2 \lambda_{55}^{*}\right)+2 a_{1}\left(\lambda_{12}^{*}+2 \lambda_{66}^{*}\right) ; \\
& \left\langle\lambda_{33}^{*}\right\rangle=3 a_{2}\left(\lambda_{11}^{*}+\lambda_{22}^{*}\right)+a_{4} \lambda_{33}^{*}+2 a_{5}\left(\lambda_{23}^{*}+\lambda_{13}^{*}+2 \lambda_{44}^{*}+2 \lambda_{55}^{*}\right)+2 a_{2}\left(\lambda_{12}^{*}+2 \lambda_{66}^{*}\right) \text {; } \\
& \left\langle\lambda_{23}^{*}\right\rangle=\left\langle\lambda_{13}^{*}\right\rangle=a_{3}\left(\lambda_{11}^{*}+\lambda_{22}^{*}\right)+a_{5} \lambda_{33}^{*}+2\left(a_{6}+a_{2}\right)\left(\lambda_{13}^{*}+\lambda_{23}^{*}\right)+2\left(a_{3}+a_{5}\right) \lambda_{12}^{*} \\
& -2 a_{2}\left(\lambda_{44}^{*}+\lambda_{55}^{*}\right)-2 a_{7} \lambda_{66}^{*} \\
& \left\langle\lambda_{44}^{*}\right\rangle=\left\langle\lambda_{55}^{*}\right\rangle=a_{3}\left(\lambda_{11}^{*}+\lambda_{22}^{*}\right)+a_{5} \lambda_{33}^{*}-a_{5}\left(\lambda_{13}^{*}+\lambda_{23}^{*}\right)-a_{2} \lambda_{12}^{*}+\left(2 a_{6}+2 a_{2}-a_{5}\right)\left(\lambda_{44}^{*}+\lambda_{55}^{*}\right) \\
& +\left(2 a_{3}+a_{2}\right) \lambda_{66}^{*} \\
& \left\langle\lambda_{66}^{*}\right\rangle=1 / 2\left(\left\langle\lambda_{11}^{*}\right\rangle-\left\langle\lambda_{22}^{*}\right\rangle\right) \\
& \left\langle\beta_{11}^{*}\right\rangle=\left\langle\beta_{22}^{*}\right\rangle=a_{8}\left(\beta_{11}^{*}+\beta_{22}^{*}\right)+a_{9} \beta_{33}^{*} ; \quad\left\langle\beta_{33}^{*}\right\rangle=a_{9}\left(\beta_{11}^{*}+\beta_{22}^{*}\right)+a_{10} \beta_{33}^{*} .
\end{aligned}
$$

Here, the coefficients $a_{i}(i=1, \ldots, 10)$ take the form [25-27]:

$$
\begin{aligned}
& a_{1}=1 / 960\left(64+19 \cos \theta^{*}+19 \cos ^{2} \theta^{*}+9 \cos ^{3} \theta^{*}+9 \cos ^{4} \theta^{*}\right) ; \\
& a_{2}=1 / 120\left(8-7 \cos \theta^{*}-7 \cos ^{2} \theta^{*}+3 \cos ^{3} \theta^{*}+3 \cos ^{4} \theta^{*}\right) ; \\
& a_{3}=1 / 240\left(16+\cos \theta^{*}+\cos ^{2} \theta^{*}-9 \cos ^{3} \theta^{*}-9 \cos ^{4} \theta^{*}\right) ; \\
& a_{4}=1 / 5\left(1+\cos \theta^{*}+\cos ^{2} \theta^{*}+\cos ^{3} \theta^{*}+\cos ^{4} \theta^{*}\right) ; \\
& a_{5}=1 / 30\left(2+2 \cos \theta^{*}+2 \cos ^{2} \theta^{*}-3 \cos ^{3} \theta^{*}-3 \cos ^{4} \theta^{*}\right) ;
\end{aligned}
$$




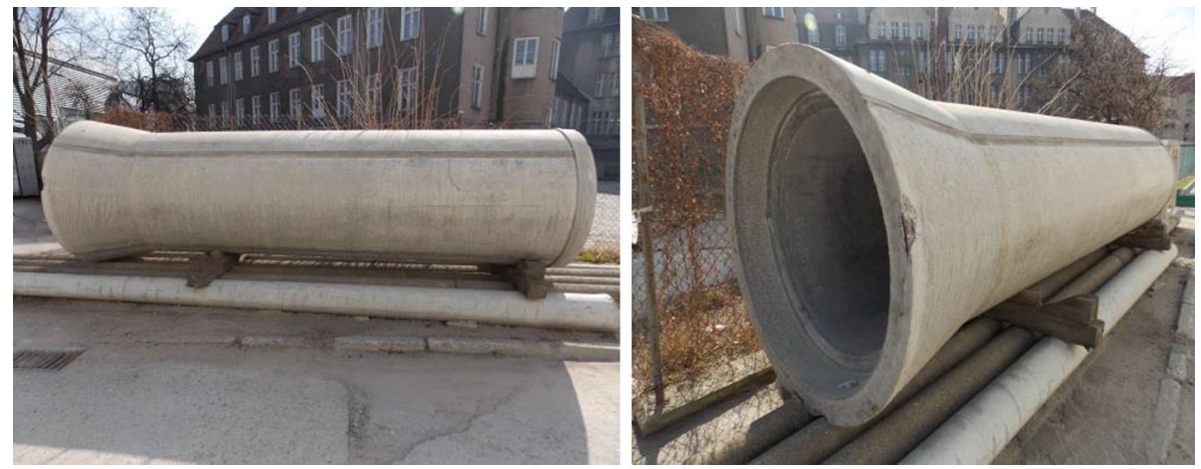

Fig. 8 View of the city collector impregnated with special polymerized sulfur

Table 2 Composition of the concrete of city collector

\begin{tabular}{lc}
\hline Components $\left(\mathrm{kg} / \mathrm{m}^{3}\right)$ & C30/37 (B37) \\
\hline Aggregate 0-2 mm & 760 \\
Aggregate 2-8 mm & 332 \\
Aggregate 8-16 mm & 674 \\
CEM I 32.5R & 372 \\
Water & 212 \\
w/c & 0.57 \\
\hline
\end{tabular}

$$
\begin{aligned}
a_{6} & =1 / 120\left(8+8 \cos \theta^{*}+8 \cos ^{2} \theta^{*}+3 \cos ^{3} \theta^{*}+3 \cos ^{4} \theta^{*}\right) ; \\
a_{7} & =1 / 480\left(32+47 \cos \theta^{*}+47 \cos ^{2} \theta^{*}-3 \cos ^{3} \theta^{*}-3 \cos ^{4} \theta^{*}\right) ; \\
a_{8} & =1 / 12\left(4+\cos \theta^{*}+\cos ^{2} \theta^{*}\right) ; \quad a_{9}=1 / 6\left(2-\cos \theta^{*}-\cos ^{2} \theta^{*}\right) ; \\
a_{10} & =1 / 3\left(1+\cos \theta^{*}+\cos ^{2} \theta^{*}\right) .
\end{aligned}
$$

Thus, it is evident from the obtained relations that such a special polymer sulfur composites is transversely isotropic. Note that when $\theta^{*}=\pi / 2$, the case in which the inclusions are uniformly disoriented is obtained [25-27]. In fact

$$
a_{1}=a_{2}=a_{3}=a_{5}=a_{6}=a_{7}=1 / 15 ; \quad a_{4}=1 / 5 ; \quad a_{8}=a_{9}=a_{10}=1 / 3
$$

and Eq. (17) reduces to Eq. (11).

Setting $\theta^{*}=0$ in Eq. (18) yields the case in which the ellipsoidal inclusions are uniformly disoriented in the plane $x_{1}^{\prime} x_{2}^{\prime}$ but still oriented along the axis $x_{3}^{\prime}$. In this case [25-27]:

$$
a_{1}=1 / 8 ; \quad a_{2}=a_{3}=a_{5}=a_{9}=0 ; \quad a_{4}=a_{10}=1 ; \quad a_{6}=a_{7}=1 / 4 ; \quad a_{8}=1 / 2 .
$$

Then, taking into account Eq. (20), Eq. (17) may be written in the form [25-27]:

$$
\begin{aligned}
& \left.\left\langle\lambda_{11}^{*}\right\rangle=\left\langle\lambda_{22}^{*}\right\rangle=3 / 8\left(\lambda_{11}^{*}+\lambda_{22}^{*}\right)+1 / 4 \lambda_{12}^{*}+1 / 2 \lambda_{66}^{*}\right) ;\left\langle\lambda_{33}^{*}\right\rangle=\lambda_{33}^{*} ; \\
& \left.\left\langle\lambda_{13}^{*}\right\rangle=\left\langle\lambda_{23}^{*}\right\rangle=1 / 2\left(\lambda_{13}^{*}+\lambda_{23}^{*}\right) ;\left\langle\lambda_{12}^{*}\right\rangle=1 / 8\left(\lambda_{11}^{*}+\lambda_{22}^{*}\right)+3 / 4 \lambda_{12}^{*}-1 / 2 \lambda_{66}^{*}\right) ; \\
& \left\langle\lambda_{44}^{*}\right\rangle=\left\langle\lambda_{55}^{*}\right\rangle=1 / 2\left(\lambda_{44}^{*}+\lambda_{55}^{*}\right) ;\left\langle\lambda_{66}^{*}\right\rangle=1 / 2\left(\left\langle\lambda_{11}^{*}\right\rangle-\left\langle\lambda_{22}^{*}\right\rangle\right) ; \\
& \left\langle\beta_{11}^{*}\right\rangle=\left\langle\beta_{22}^{*}\right\rangle=1 / 2\left(\beta_{11}^{*}+\beta_{22}^{*}\right) ;\left\langle\beta_{33}^{*}\right\rangle=\beta_{33}^{*} .
\end{aligned}
$$

Note also that these formulas may be obtained directly from Eq. (9), taking into account that the distribution function for inclusions, disoriented in the plane $x_{1}^{\prime} x_{2}^{\prime}$, takes the form [25-27]:

$$
f(\theta, \varphi, \psi)=4 \pi \delta(\theta) \delta(\psi) / \sin (\theta) .
$$

Now consider the case in which inclusions are uniformly and continuously distributed in the interval $0 \leq \theta<\theta^{*}, 0 \leq \varphi<2 \pi$, and $\psi=0$. In this case, $f(\theta, \varphi, \psi)$ takes the form [25-27]:

$$
f(\theta, \varphi, \psi)=b h_{\theta^{*}}(\theta) \delta(\psi) .
$$


Here, $h_{\theta^{*}}(\theta)$ is the indicator function of the angle $\theta$ in Eq. (13) and $b$ is found from the normalization condition (14) [25-27]:

$$
b=\frac{4 \pi}{1-\cos \theta^{*}} .
$$

Then, Eq. (23) may be written in the form [25-27]:

$$
f(\theta, \varphi, \psi)=\frac{4 \pi}{1-\cos \theta^{*}} h_{\theta^{*}}(\theta) \delta(\psi)
$$

Without going through the details of the calculations, the mean elastic moduli in this case may be written in the form [25-27]:

$$
\begin{aligned}
& \left\langle\lambda_{11}^{*}\right\rangle=\left\langle\lambda_{22}^{*}\right\rangle=3 a_{1} \lambda_{11}^{*}+3 a_{2} \lambda_{22}^{*}+3 a_{4} \lambda_{33}^{*}+6 a_{5}\left(\lambda_{23}^{*}+2 \lambda_{44}^{*}\right)+2 a_{3}\left(\lambda_{13}^{*}+2 \lambda_{55}^{*}\right)+2 a_{1}\left(\lambda_{12}^{*}+2 \lambda_{66}^{*}\right) ; \\
& \left\langle\lambda_{33}^{*}\right\rangle=8 a_{4} \lambda_{22}^{*}+8 a_{2} \lambda_{33}^{*}+16 a_{5}\left(\lambda_{23}^{*}+2 \lambda_{44}^{*}\right) ;\left\langle\lambda_{66}^{*}\right\rangle=1 / 2\left(\left\langle\lambda_{11}^{*}\right\rangle-\left\langle\lambda_{22}^{*}\right\rangle\right) ; \\
& \left\langle\lambda_{23}^{*}\right\rangle=\left\langle\lambda_{13}^{*}\right\rangle=4 a_{5}\left(\lambda_{22}^{*}+\lambda_{33}^{*}\right)+4\left(a_{2}+a_{4}\right) \lambda_{23}^{*}+4 a_{1} \lambda_{13}^{*}+4 a_{3} \lambda_{12}^{*}-4 a_{5} \lambda_{44}^{*} ; \\
& \left\langle\lambda_{12}^{*}\right\rangle=a_{1} \lambda_{11}^{*}+a_{2} \lambda_{22}^{*}+a_{4} \lambda_{33}^{*}+2 a_{5} \lambda_{23}^{*}+6 a_{3} \lambda_{13}^{*}+6 a_{1} \lambda_{12}^{*}+4 a_{5} \lambda_{44}^{*}-4 a_{3} \lambda_{55}^{*}-4 a_{1} \lambda_{66}^{*} ; \\
& \left.\left\langle\lambda_{44}^{*}\right\rangle=\left\langle\lambda_{55}^{*}\right\rangle=4 a_{5}\left(\lambda_{221}^{*}+\lambda_{33}^{*}-2 \lambda_{23}^{*}\right)+4\left(a_{2}+a_{4}-2 a_{5}\right) \lambda_{44}^{*}+4 a_{1} \lambda_{55}^{*}+4 a_{3} \lambda_{66}^{*}\right) ; \\
& \left\langle\beta_{11}^{*}\right\rangle=\left\langle\beta_{22}^{*}\right\rangle=a_{6}\left(\beta_{11}^{*}+\beta_{22}^{*}\right)+a_{7} \beta_{33}^{*} ;\left\langle\beta_{33}^{*}\right\rangle=a_{7}\left(\beta_{11}^{*}+\beta_{22}^{*}\right)+a_{8} \beta_{33}^{*} .
\end{aligned}
$$

Here,

$$
\begin{aligned}
& a_{1}=1 / 24\left(1+\cos \theta^{*}+\cos ^{2} \theta^{*}\right) ; \quad a_{3}=1 / 24\left(2-\cos \theta^{*}-\cos ^{2} \theta^{*}\right) ; \\
& a_{2}=1 / 40\left(1+\cos \theta^{*}+\cos ^{2} \theta^{*}+\cos ^{3} \theta^{*}+\cos ^{4} \theta^{*}\right) ; \\
& a_{4}=1 / 120\left(8-7 \cos \theta^{*}-7 \cos ^{2} \theta^{*}+3 \cos ^{3} \theta^{*}+3 \cos ^{4} \theta^{*}\right) ; \\
& a_{5}=1 / 120\left(2+2 \cos \theta^{*}+2 \cos ^{2} \theta^{*}-3 \cos ^{3} \theta^{*}-3 \cos ^{4} \theta^{*}\right) ; \\
& a_{6}=1 / 2 ; \quad a_{7}=1 / 6\left(2-\cos \theta^{*}-\cos ^{2} \theta^{*}\right) ; \quad a_{8}=1 / 3\left(1+\cos \theta^{*}+\cos ^{2} \theta^{*}\right) .
\end{aligned}
$$

Setting $\theta^{*}=0$ in Eq. (18) yields the case in which the ellipsoidal inclusions are uniformly disoriented in the plane $x_{1}^{\prime} x_{2}^{\prime}$ but oriented along the axis $x_{3}^{\prime}$. In this case [25-27]:

$$
a_{1}=a_{2}=1 / 8 ; \quad a_{3}=a_{4}=a_{5}=a_{7}=0 ; \quad a_{6}=1 / 2 ; \quad a_{8}=1 / 3 .
$$

Then, taking into account Eq. (28), Eq. (26) reduces to Eq. (21).

The mean plastic-pliability matrix $\left\langle S_{i j}^{*}\right\rangle$ and the coefficients of linear thermal expansion $\left\langle\alpha_{m n}^{*}\right\rangle$, corresponding to Rice averaging, may be calculated analogously [25-27].

\subsection{Numerical investigations: results analysis}

As a numerical example, consider an arbolite based on straw particles and pores in special polymer sulfur composites with the plastic constants, respectively [25-27]:

$$
\begin{aligned}
E_{1}^{(1)} & =0.5 \cdot 10^{-9} \mathrm{~Pa} ; \quad E_{2}^{(1)}=0.3 \cdot 10^{-9} \mathrm{~Pa} ; \quad E_{3}^{(1)}=6 \cdot 10^{-9} \mathrm{~Pa} ; \quad G_{23}^{(1)}=0.3 \cdot 10^{-9} \mathrm{~Pa} ; \\
G_{13}^{(1)} & =0.36 \cdot 10^{-9} \mathrm{~Pa} ; \\
G_{12}^{(1)} & =0.09 \cdot 10^{-9} \mathrm{~Pa} ; \quad v_{23}^{(1)}=0.025 ; \\
v_{13}^{(1)} & =0.3 ; v_{12}^{(1)}=0.6 ; \quad E^{(2)}=30 \cdot 10^{-9} \mathrm{~Pa} ; \quad v^{(2)}=0.2 ; \quad k_{2}=0.1 ; \quad k_{3}=10 ; \quad c_{0}=0.1 . \quad[18-20]
\end{aligned}
$$

Here, $k_{2}$ and $k_{3}$ are the ratio of the semi-axes of ellipsoids (these parameters characterize the dimension of inclusions) and $c_{0}$ is the concentration of the pores in special polymer sulfur composites [25-27].

The results in Fig. 9 are calculated by the Voigt scheme. The dependencies of Young's modulus $\left\langle E_{3}^{*}\right\rangle$, Poisson's ratio $\left\langle v_{12}^{*}\right\rangle$, and shear modulus $\left\langle G_{12}^{*}\right\rangle$ from concentration of inclusions $c_{1}$ and for certain values of $k_{2}, k_{3}$ 


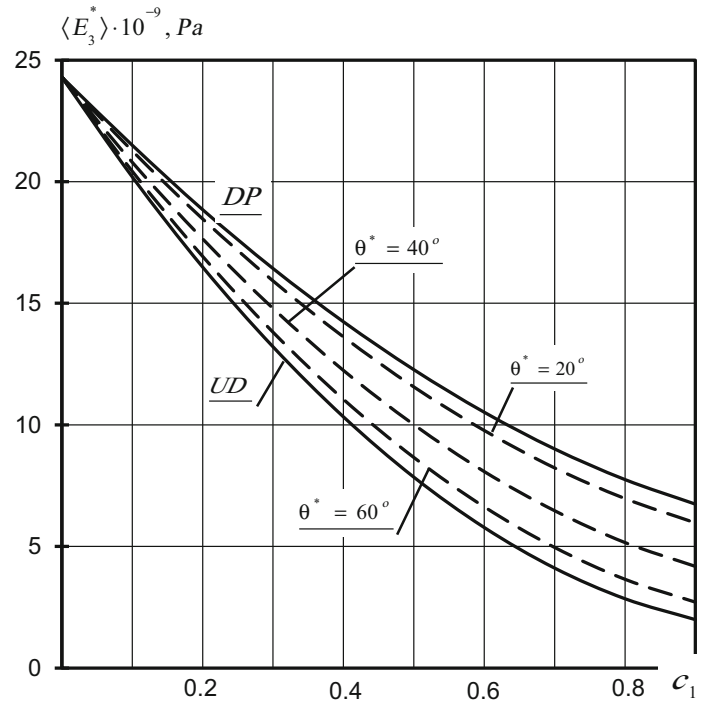

(a)

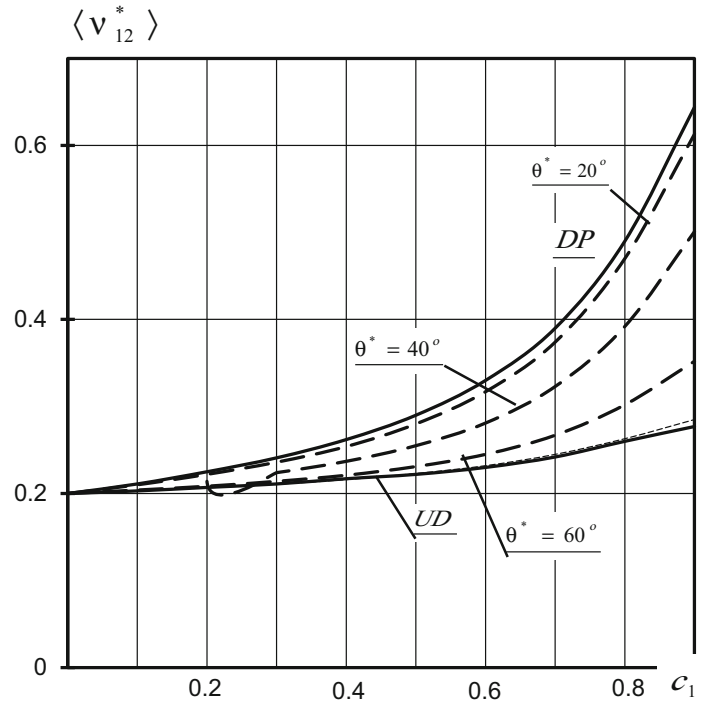

(b)

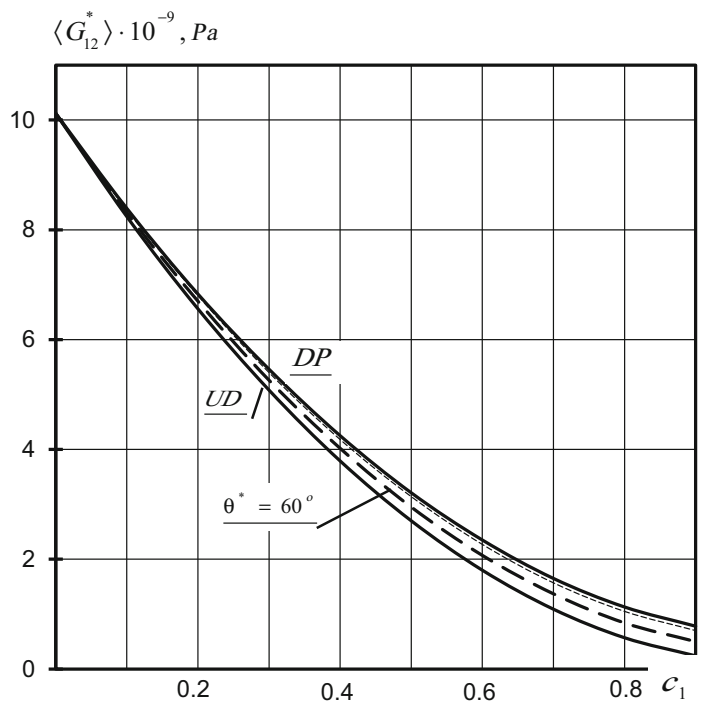

(c)

Fig. 9 a A view the dependencies of Young's modulus $\left\langle E_{3}^{*}\right\rangle$, b Poisson's ratio $\left\langle v_{12}^{*}\right\rangle$, and $\mathbf{c}$ shear modulus $\left\langle G_{12}^{*}\right\rangle$ from concentration of inclusions $c_{1}$ and for certain values of $k_{2}, k_{3}$ are calculated by the Voigt scheme [25-27]

are shown in Fig. 10. The continuous curves correspond to uniform disorientation of the inclusions (UD) and disorientation of ellipsoids in the plane $x_{1}^{\prime} x_{2}^{\prime}$ (DP), and the dashed curves correspond to the case when the inclusions are uniformly and continuously distributed within the interval $0 \leq \theta<\theta^{*}, 0 \leq \varphi<2 \pi, 0 \leq \psi<2 \pi$, where $\theta^{*}=20^{\circ}, 40^{\circ}, 60^{\circ}, 80^{\circ}$ [25-27].

Analogous results given by the Rice scheme are shown in Fig. 10. It is evident from the graphs that the numerical values of the macroscopic constants $\left\langle E_{3}^{*}\right\rangle,\left\langle G_{12}^{*}\right\rangle$ given by Voigt averaging are higher than those given by Rice averaging for all concentrations of the reinforcing inclusions [25-27].

The dependence of the constant $\left\langle v_{12}^{*}\right\rangle$ is more complicated in character. Note also that the greatest discrepancy corresponds to concentrations of inclusions in the range 0.3-0.7. In some cases of considerable discrepancy between the Voigt and Rice results, the Hill approximation may be used, i.e., the arithmetic mean of the Voigt and Rice values [25-27]. 


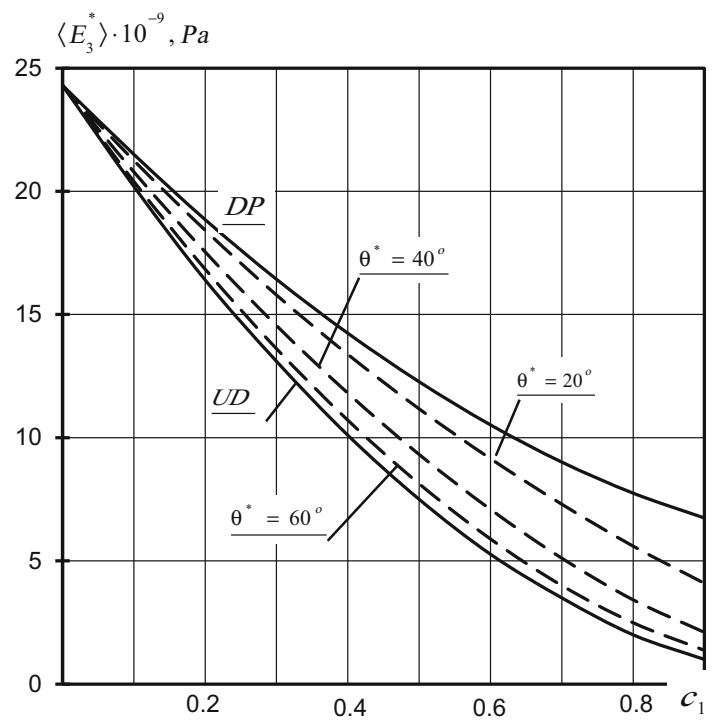

(a)

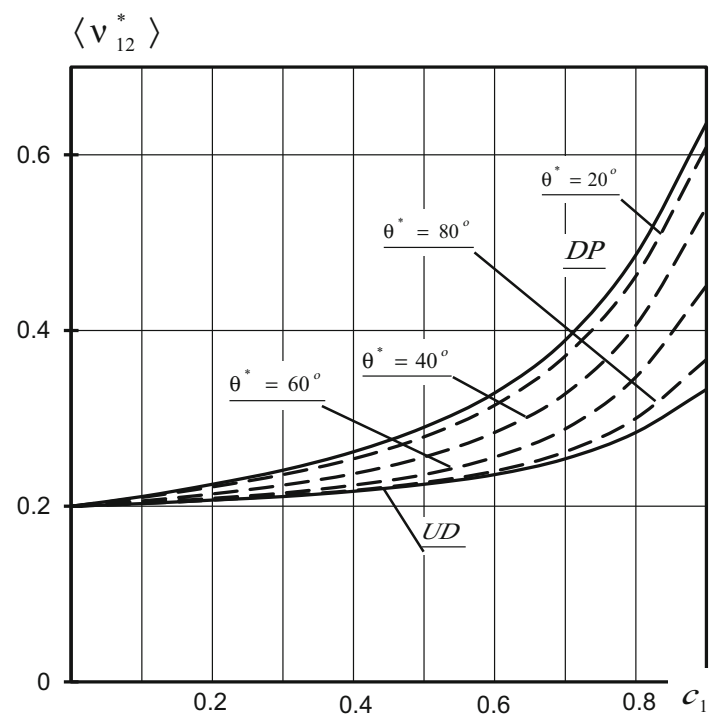

(b)

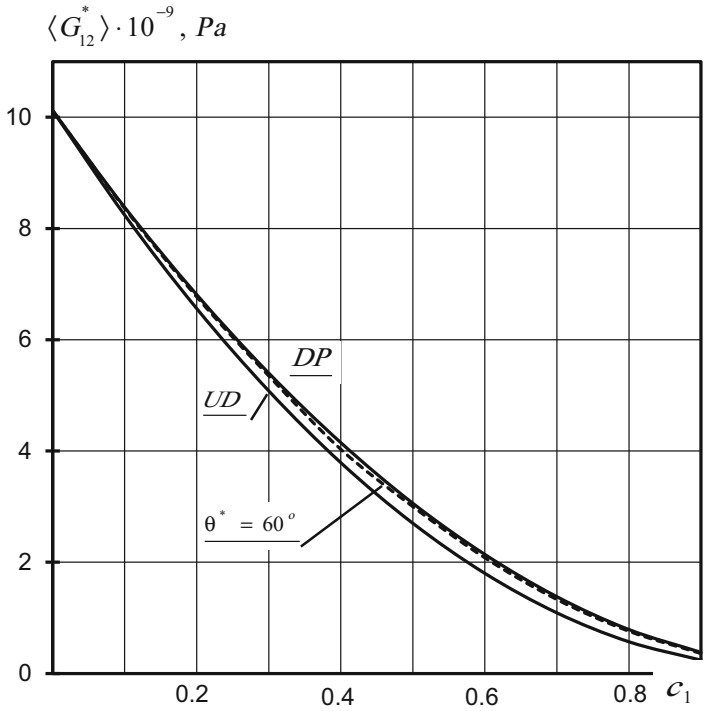

(c)

Fig. 10 a A view the dependencies of Young's modulus $\left\langle E_{3}^{*}\right\rangle$, b Poisson's ratio $\left\langle v_{12}^{*}\right\rangle$, and $\mathbf{c}$ shear modulus $\left\langle G_{12}^{*}\right\rangle$ from concentration of inclusions $c_{1}$ and for certain values of $k_{2}, k_{3}$ are calculated by the Rice scheme [25-27]

Research was also successful in developing processes for partial depth impregnation that could be used in the field for impregnating bridge decks and other cement composite surfaces. The process required drying the concrete to remove moisture from the surface, applying the special polymerized sulfur on a thin sand layer that held the special polymerized sulfur during the time the monomer was being imbibed into the concrete, and then polymerizing the monomer using steam heat. The process was capable of producing impregnated depths of $10-50 \mathrm{~mm}$. The concrete surfaces were much more resistant to water absorption, had much higher abrasion resistance, and in general were much more durable. The downside was that the process normally took about one day and subjected the concrete to high temperatures (thermal process) during drying that resulted in micro cracking, and was rather cumbersome. Many bridge decks in Poland were successfully impregnated during 1980-1985, but the development of polymer concrete overlays provided a simpler, faster, and less costly method for waterproofing concrete surfaces. 
More recently, however, there has been a successful commercial application of partial depth impregnation. The special polymerized sulfur vacuum impregnation system uses a thermoplastic membrane that is applied over the surface of a slab, statue, column, or wall, and vacuum is used to evacuate the air from the pores.

\section{Summary and conclusion}

The process of applying special polymerized sulfur composite from industrial waste production is a thermal treatment process in the temperature of about $150-155^{\circ} \mathrm{C}$. The result of such a treatment is special polymerized sulfur composite in a liquid state (thermoplastic properties). Special polymerized sulfur (polymer coating) in a liquid state is mixed with a previously heated extender (thermal processes).

This paper presents methods and results for determining the effective thermoplastic constants of special polymer sulfur composites with their isotropic porous matrix reinforced by disoriented ellipsoidal orthotropic inclusions. The method is based on the use of conditional statistical averaging and permits determining effective properties of essentially inhomogeneous special polymer sulfur composites possessing geometrical and physical anisotropy. The solution is constructed in two stages. First, the problem of the effective properties of special polymer sulfur composites with randomly distributed and oriented inclusions is solved. Then, the problem of the effective properties of these composites is solved on the basis of the Voigt or Rice scheme. The effect of shape and concentration of the inclusions, concentration of pores in the matrix and the type of inclusion orientation has been studied [25-27].

The presented state of the art in the area of the PIC (special polymerized sulfur (polymer coating)impregnated cement composites) shows the material complexity of the subject and the gap between polymer concretes and Portland cement concretes regarding standardization, formal guidelines for production, and recommendation for use. This determines the need for further works.

Recent research has led to the development of durable special polymerized sulfur building mortars, concretes, and coatings. All the methods of using special polymerized sulfur as a binder for rigid concrete rely on the reaction of one or more modifiers to stabilize, in the hardened state, at least a portion of the special polymerized sulfur in its less brittle, less dense form. The durability of the concrete produced appears to depend on the modifying system used. In all the cases, the special polymerized sulfur must be heated to a liquid state to react with the modifier and to mix with and coat the aggregate and filler.

Special polymerized sulfur (polymer coating)-impregnated cement composites can develop high strength, attain strength in $0.5 \mathrm{~h}$, require no special curing, resist acids and organic liquids, have no known undesirable reactions with aggregates, and require no limitation on the ambient temperature at the time of placement. When its use becomes economically feasible, concrete-impregnated special polymerized sulfur (polymer coating) will be an excellent material for use in pavement repairs and bridge deck overlays.

Solidified impregnant in the small pores of solids are normally in metastable equilibrium. Spatial restrictions prohibit the formation of regular crystal habit. Because of the formation of noncrystalline modifications, the free energy is increased. In addition, owing to the large surface-to-volume ratio, the surface free energy is also large. In the absence of concave menisci or strong interaction with the matrix that would reduce the energy, the tendency for spontaneous exudation from the pores is increased.

Special polymerized sulfur (polymer coating) does not interact strongly with siliceous surfaces, so that water or other liquids can penetrate the porous network and adsorb on the substrate surface, weakening further the interaction between it and sulfur. Water adsorbs also on sulfur, creating a lubricating effect and high stresses due to surface energy decrease. Both effects facilitate extrusion, and the latter causes destruction.

Because of the relatively slow penetration of water, nonisotropic expansion creates strains beyond the plastic limits.

Impregnated porous solids of small size can be successfully utilized for predicting the behavior of largesized systems.

Cement composites impregnated with special polymerized sulfur (polymer coating) are widely and successfully used in the repairs of reinforced concrete structures as well as in their surface protection. Polymer mortars and mortars impregnated with special polymerized sulfur coating are used for making industrial floors. The main advantages here are excellent adhesion to various materials, tightness, and frost resistance, and in the case of the resin concretes also, a short time to exploitation readiness as discussed elsewhere [5,15,26]. The limitation can be relatively high setting shrinkage, a well as some differences between the properties of the repaired concrete and the repair material — particularly high thermal expansion, creep, and sometimes limited thermal resistance and aging resistance. 


\section{Compliance with ethical standards}

Conflict of interest The author declares and assures that no conflict exists.

Open Access This article is distributed under the terms of the Creative Commons Attribution 4.0 International License (http:// creativecommons.org/licenses/by/4.0/), which permits unrestricted use, distribution, and reproduction in any medium, provided you give appropriate credit to the original author(s) and the source, provide a link to the Creative Commons license, and indicate if changes were made.

\section{References}

1. Czarnecki, L., Garbacz, A.: Evaluation of polymer coating-crack-bridging ability. International Colloquium "Industrial Floors" 95, Esslingen (1995)

2. Hoła, J., Książek, M.: Research on usability of sulphur polymer composite for corrosion protection of reinforcing steel in concrete. Arch. Civ. Mech. Eng. 9(1), 47-59 (2009). http://www.acme.pwr.wroc.pl/repository/230/online.pdf

3. Hoła, J., Schabowicz, K.: New technique of nondestructive assessment of concrete strength using artificial intelligence. NDT \& E Int. 38(4), 251-259 (2005)

4. Kamiński, M., Musiał, M., Ubysz, A.: Eigenfrequencies of the reinforced concrete beams-methods of calculations. J. Civ. Eng. Manag. 17(2), 278-283 (2011). http://www.tandfonline.com/doi/abs/10.3846/13923730.2011.576812

5. Książek, M.: Use in the building cement composites impregnated with special polymerized sulfur. J. Build. Eng. 4, 255-267 (2015). doi:10.1016/j.jobe.2015.09.007

6. Książek, M.: The experimental research on properties, structures and applies polymer sulfur composites as the industrial waste material in the industry objects. Mater. Struct. 48(10), 3269-3278 (2015). doi:10.1617/s11527-014-0397-1

7. Książek, M.: The experimental research on special polymerized sulfur composite-impregnated concrete and cement mortar. J. Mater. Sci. Eng. 4, 160 (2015). doi:10.4172/2169-0022.1000160

8. Książek, M.: Biological corrosion of the sandstone of the quay of the river of Odra in Wrocław. Eng. Fail. Anal. 44, 338-344 (2014). doi:10.1016/j.engfailanal.2014.05.003

9. Książek, M.: The biocorrosion of city sewer collector impregnated special polymer sulfur binder-polymerized sulfur applied as the industrial waste material. Constr. Build. Mater. 68, 558-564 (2014). doi:10.1016/j.conbuildmat.2014.06.077

10. Książek, M.: The influence of penetrating special polymer sulfur binder-polymerized sulfur applied as the industrial waste material on concrete watertightness. Compos. Part B Eng. 62(62C), 137-142 (2014). doi:10.1016/j.compositesb.2014.02. 027

11. Książek, M.: The evaluate tendencies of corrosion process for reinforcing steel when covered with special polymer sulfur coating. Eng. Fail. Anal. 39, 1-11 (2014). doi:10.1016/j.engfailanal.2014.01.005

12. Książek, M.: The experimental investigations of propriety and applies in the building special coating-sulphur polymer composite as the industrial waste material. Compos. Part B Eng. 58(58C), 378-385 (2014). doi:10.1016/j.compositesb.2013. 10.087

13. Książek, M.: City sewer collectors biocorrosion. Central Eur. J. Eng. 4(4), 398-407 (2014). doi:10.2478/s13531-013-01777

14. Książek, M.: The experimental research on properties, structures and applies polymer sulfur composites as the industrial waste material in the industry objects. Mater. Struct. RILEM (2014). doi:10.1617/s11527-014-0397-1

15. Książek, M.: The intensity of corrosion processes influenced by tensile stress for reinforcing steel covered with sulphur polymer composite applied as industrial waste material. Compos. Part B Eng. 45(1), 1126-1132 (2013). doi:10.1016/j. compositesb.2012.04.072

16. Książek, M.: The experimental and innovative research on intensity of corrosion processes influenced by tensile stress for reinforcing steel covered with sulphur polymer composite applied as industrial waste material. Adv. Sci. Lett. 19(1), 247-251 (2013). doi:10.1166/asl.2013.4652

17. Książek, M.: Experimental research on the surface protection of concrete by polymer sulfur composite. Mag. Concrete Res. 64(10), 945-955 (2012). doi:10.1680/macr.11.00142

18. Książek, M.: The experimental and innovative research on usability of sulphur polymer composite for corrosion protection of reinforcing steel and concrete. Compos. Part B Eng. 42(5), 1084-1096 (2011). doi:10.1016/j.compositesb.2011.03.022

19. Książek, M.: The experimental research on polarization of tensioned rebars coated with sulphur polymer composite. In: 10th Youth Symposium on Experimental Solid Mechanics, Chemnitz, 25th-28th May 2011. Institute of Mechanics and Thermodynamics, pp. 67-68. Department of Solid Mechanics, Chemnitz University of Technology (2011)

20. Książek, M.: Experimental research of the intensity of corrosion processes influence by tensile stress for reinforcing steel covered with polymer sulphur composites. In: Concrete Solutions: Proceedings of Concrete Solutions. 4th International Conference on Concrete Repair, Dresden, Germany, 26-28 September 2011, pp. 257-265 (2012)

21. Książek, M.: The mechanical destruction of sulphur composites [Niszczenie mechaniczne kompozytów siarkowych]. Prace Naukowe Instytutu Budownictwa Politechniki Wroclawskiej 03249875(80), 105-112 (2001)

22. Książek M., The sulphur binders - Their potential possibilities of using in buildings [Spoiwa siarkowe - Ich potencjalne możliwości zastosowań w budownictwie]. Prace Naukowe Instytutu Budownictwa Politechniki Wroclawskiej, ISSN: 03249875, Issue 75, CONFERENCE NO. 26, pp. 77-78 (1999)

23. Ramli, M., Amin, A.T.: Porosity, pore structure and water absorption of polymer-modified mortars: an experimental study under different curing conditions. Compos. Part B Eng. 55, 221-233 (2013). doi:10.1016/j.compositesb.2013.06.022

24. Vlahović, M.M., Jovanić, P.B., Martinović, S.P., Boljanac, T.D., Volkov-Husović, T.D.: Quantitative evaluation of sulfurpolymer matrix composite quality. Compos. Part B Eng. 44(1), 458-466 (2013). doi:10.1016/j.compositesb.2012.04.005 
25. Nazarenko, L.V.: Models of coupled deformation and microdamaging of anisotropic composite materials of stochastic structure. DSci Thesis, 2009, S.P.Timoshenko Institute of Mechanics of the National Academy of Sciences of Ukraine, Kyiv

26. Nazarenko, L.V.: Thermoelasticity of matrix composite with disoriented orthotropic inclusions. In: Nazarenko, L.V. (ed) Proceedings of 7th International Conference Modern Building Materials, Structures and Techniques, Vilnius, Lithuania, pp. 322-324 (2001)

27. Nazarenko, L.V.: Investigation of effective thermoelastic properties of stochastic composite materials, ISSN: 03249875, Issue 75. CONFERENCE NO. 26, 115-122 (1999) 